\title{
Evaluation on Northern Sea Route Navigation Environment
}

\author{
Liu Yiying, \\ Transportation Management College \\ Dalian Maritime University \\ Dalian, China \\ liuyiying976@163.com \\ Fan Houming \\ Transportation Management College \\ Dalian Maritime University \\ Dalian, China \\ fhm468@163.com
}

\author{
Jiang Xiaodan \\ Transportation Management College \\ Dalian Maritime University \\ Dalian, China \\ jxddlmu@163.com \\ Zhao Qiqi \\ Transportation Management College \\ Dalian Maritime University \\ Dalian, China \\ annanaqq@163.com
}

\begin{abstract}
Northern Sea Route is known as a new route with complex navigation environment. It will greatly shorten the distance between the Far East and Europe. This article systematically analyzes the sailing conditions of Northern Sea Route and the main factors that influence the navigation environment. An evaluation index system is established. According to the fuzzy and gray characteristics of the evaluation index, the grey-cloud clustering model is built up and an actual evaluation is conducted. The results can not only enrich the relevance theory of polar research, but also provide reference for our country to make relevant strategic decisions on Northern Sea Route.
\end{abstract}

Keywords- Northern Sea Route; Navigation environment; Grey cloud; Clustering; Evaluation

\section{INTRODUCTION}

As global warming intensifies and the melting rate of Arctic ice speeds up, the perspective of navigation via Northern Sea Route (NSR) will become more realistic. According to Arctic Climate Impact Assessment and the 2007 Fourth Assessment Report of the Intergovernmental Panel on Climate Change (IPCC), the area covered by Arctic ice has been continuingly receding in the $21^{\text {st }}$ century. In addition, referring to the latest prediction, the Arctic would be ice-free in the summer of 2037[1] for the first time. The Northeast Route is one of three Arctic maritime routes, the others being the Northwest Route and the Transpolar Route[2]. Comparing to Northwestern Route and the Transpolar Route, NSR is the one with the fastest ice shrinking rate. This would make NSR the first to open commercial navigation. What's more, it's important that geographical location will make it the ninth ocean route for China[3]. Hence, the research towards NSR navigation environment in this article has practical significance.

The main part of NSR is running along the Russian Arctic coast (Fig.1). It traverses (from West to East) the Barents Sea, Kara Sea, Laptev Sea, East Siberian Sea, and Chukchi Sea, to the Bering Strait. Once the route become commercially navigable, it will shorten the ocean route between Far East and European Continent from 13000miles to 7900miles[4-5]. This can be time and cost saving.

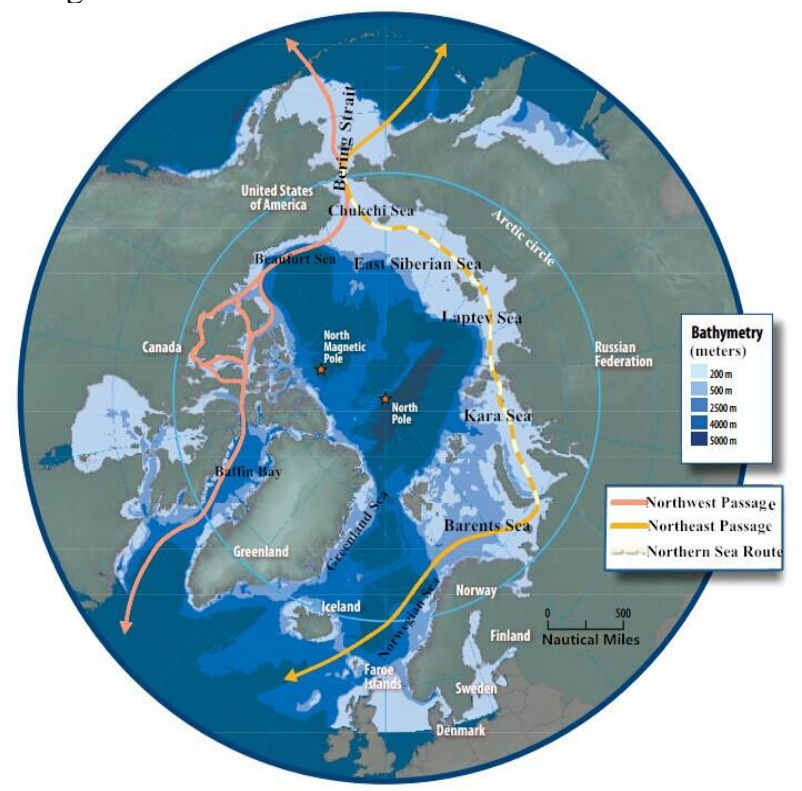

Figure 1. The sketch diagram of North Sea Route

Since the Finnish crude oil tanker Uikku first made the transit via NSR in 1997, the number of merchant ships navigating through NSR has increased gradually. NSR has emerged as a new main route linking Asia and Europe. In July, 2009, two cargo ships Beluga Fraternity and Beluga Foresight, commencing a northward voyage from Korea, passed the Vladivostok port and went through NSR which was frozen for a long time while finally arrived in Rotterdam successfully[6]. On August 8, 2013, Yongsheng of Cosco began its voyage from Taicang port, China. After sailing for 27 days through 7800 miles, the vessel 
reached Rotterdam in September, 10 during which also sailed through NSR. This is the first time that Chinese merchant ships sailed through the Arctic routes to Western Europe, which is of historical significance[7]. More and more countries are showing their interests in NSR at present. But, the Arctic is sparsely populated and experiencing severe natural conditions, with a lot of frozen channels. Also, the political situations of the costal countries are complex. Nevertheless, the situation of lacking of necessary navigation aid and navigation experience in the north-pole is still severe, which makes navigation in the Arctic Ocean even more dangerous[8]. This article analyses and evaluates the navigation environment of NSR which provides a scientific reference for the coming safe NSR navigation and its effective development.

\section{ANALYSIS ON INFLUENCE FACTORS OF NSR SAILING CONDITION}

Navigation is a complex human-machine-environment system based on human operation[8]. It uses boat and navigation environment as subject and object respectively. Among the concepts, navigation environment is the sum of natural and human environment with which vessels are confronted [9]. Since NSR is located in a special area with a complex international situation, influences on navigation environment mentioned not only refer to sea ice, temperature and some other natural environment factors but also law and regulations, navigational aid and information intelligence environment.

\section{A. Natural Environment}

Natural environment is the main influence factor on NSR navigation. It mainly includes temperature, visibility, wind, tidal, current, depth of routes, distribution of channels, etc. The Arctic, where the NSR locates, is of low temperature along with severe natural conditions. The sea ice is thick with high intensity. Visibility of sea surface is considerably low in this area except for the Barents Sea. The navigable time is mainly from July to October.

The influences that temperature has on navigation mainly lie in the influence on handling performance of vessels due to icing in low temperature. This may also inconveniences seafarers which may also affect the navigation to some extent. In the waters that NSR pass through, Barents Sea is of a higher temperature due to the effect of North Cape Current[10]. This makes it become the warmest sea of the Arctic and more suitable for navigation. The average temperature in July of Kara Sea, Laptev Sea, East Siberian Sea and Chukchi Sea is around $8^{\circ} \mathrm{C}$. This temperature melts the sea ice and makes them proper for navigation. However, in January during which the sea surface are covered by thick ice, the average temperature of most sea areas is below $-30^{\circ} \mathrm{C}$,

Visibility, is the maximum horizontal distance that can be seen by normal visual during navigation[ 11 ]. According to relevant statistics, the negative exponential function between the number of accidents during navigation $(K)$ and visibility(D) is $K=\mathrm{D}^{-0.8}$. In the function,
$\mathrm{K}$ stands for number of accidents while D stands for the visible distance $(\mathrm{km})$. The visibility of sea surface is mainly related to duration of sunshine, rainfall, snow and fog[12].

Wind is generally accepted as the most important factor in navigation safety analyzing system. Strong wind may cause a lot of danger e.g. deviation, standing and dragging. Along with strong wind, there may also be sudden storm at sea. The average wind speed of the Arctic region is between 4-6m per second. Kara Sea and Chukchi Sea areas within NSR experiences wind storm frequently while the volatile climate of East Siberian Sea is due to the anticyclone of Asia and the Arctic.

Current (i.e. sea and tidal current) can also affect the handling performance of vessels. In narrow navigating zone, sea current and tidal current increase the relative speed between sides of upstream vessels and currents under vessel. This can lead to a bank effect which may cause collision and stranding. Generally speaking, the higher current velocity, the harder it becomes for ship navigation. The probability of traffic accident may also increase due to the same reason.

Sea ice is the leading natural influence on NSR navigation safety. The effect it has on sailing condition can be measured mainly through intensity and thickness. Generally speaking, when the intensity of sea ice is lower than $15 \%$ or the thickness is under $30 \mathrm{~cm}$, the ship can operate smoothly. In the sea area of NSR, the temperature of sea surface of Barents Sea is comparatively high, though it sometimes freezes. The ice is mostly one-yearice which is shorter in ice age and thinner comparing to those in other sea areas where sea surface are covered by snow and ice all year long. The navigable period of these areas are relatively short from August to October each year.

The depth of a channel decides the tonnage of navigable vessels. The depth of Barents Sea is 229 meters while the average depth of Kara Sea is 90 meters, with the depth of $40 \%$ of its sea area less than 50 meters. Sea Laptev, with a depth between 10-40 meters, locates $75 \%$ of its area on the continental shelf. East Siberian Sea, only 45 meters deep, is almost completely on the continental shelf while Sea Chukchi is only 88 meters deep on average with over half of its sea area less than 50 meters deep. NSR runs through 58 straits among which are 10 most important ones including three straits connecting Barents Sea and Kara Sea, four straits linking Kara Sea and Laptev Sea, two between Laptev and Eas Siberian Sea and one between East Siberian and Chukchi[13]. These 10 straits are frozen or with floating ice in most of the year which raises the difficulty of navigation.

\section{B. Laws and Regulations}

Proper laws and regulations is an important factor to ensure the navigation safety through NSR. The Arctic is rich of natural resources and of important military strategy status. This makes countries alongside the NSR legislate in terms of maximizing their own benefits. However, proper legislation should not only be confined to national 
laws, and regulations within relevant costal countries but also includes international norms of vessel sailing rules and vessel operating standards in the area, etc.

International laws and regulations towards NSR will affect greatly on the interests of every country in the world[14]. They are the basis of solving international conflicts. United Nations Conference on the Law of the Sea, on one hand, is an important means to solve Arctic conflicts. With the purpose of ensuring their advantageous positions, countries alongside the route have already came out with corresponding laws and regulations to protect their core interests. For example, Russia claimed that Northern Sea Route is its internal maritime waters and unilaterally controls the area by promulgating Rules of Navigation in the Northern Sea Route Water Area. To make sure the safe navigation in Arctic area, International Maritime Organization (IMO) drafted a set of regulations considering Arctic shipping, for example, Guidelines for Ships Operating in Arctic Ice-covered Waters and Guidelines for Ships Operating in Polar Waters. In addition, to deal with the heavy ice in the Arctic, International Association of Classification Societies (IACS) enacted Polar Class Rules which details machinery and structure requirements for Polar Class ships.

Laws related to NSR are mainly a combination of nonbinding soft laws and restrictive laws led by the sovereign states. The existed regulations of the Arctic region are aimed at specific issues. There is a lack of an integrated regulation[15]. Moreover, most of the regulations are solely related to environmental protection, leaving very few aiming at regional governance or sovereignty defining. This leaves the existing laws with low applicability, which is the fundamental cause of NSR sovereignty disputes. For the above reasons, there are still a lot of improvements could be made, considering laws and regulations of NSR.

\section{Geopolitics}

Geopolitics has significant influence on NSR. It mainly includes route sovereignty, channel command, coordinating ability of alongside countries and their political strategies. Countries are paying more attention to the economic interest and strategic value of the Arctic. The geopolitics of Arctic routes becomes extremely complicated.

Take the designation Northern Sea Route as an example. Russia named the overlap sea area between NSR and Russian sea water the Northern Sea Route. Since the very beginning, Russia has taken Northern Sea Route as its domestic water and claims that it has the juristic right over it. Russia also implemented compulsory pilotage policy on sailing pass vessels by legislation. Meanwhile, America, Norway, Denmark and some other countries insist that NSR is affiliated to international waters which should apply transit passage regulations. There is no agreement reached after multiple times of negotiations. To protect their interests from being harmed, Russia and America are both urging to develop their military power and infrastructure in the Arctic region. By December 8, 2014, Russian Ministry of Defense has accomplished its third military base in the Arctic[16]. America is now also trying the best to implement the Arctic Strategy to deal with any change of the situation. It would be hard to provide safe navigation on NSR just based on the power of Russia due to the severe climate, and complicated icing problem. The reason may also include NSR's location where its majority lies along Russia, and the trend of rapid growth in number of transits. To safely use the route, it is necessary to encourage cooperation between multiple countries to provide service and supply. Hence, all the other countries in the world should share the same right and opportunity to develop NSR.

\section{Navigation Aid and Information Intelligence Environment}

Navigation Aids Facilities and Information Intelligence Environment is the technical material which guarantees the safe use of NSR. It mainly includes hardware like icebreakers, port facilities, navaid, navigational positioning. And information materials like charts, meteorological and oceanographic broadcasts. NSR is experiencing a severe icing problem. Sailing ships should carry accurate positioning devices, request help from navigation aids and use icebreaker to open safe waterways. Ships will also need proper port facilities for berthing and feeding. Meanwhile, seafarers on board should also receive information e.g. meteorological information and sea maps of the sea in time.

Icebreakers are responsible for multiple tasks e.g. maintaining of ice-filled waterways, escorting conveys, opening sea passages and carrying out salvage operations, etc. It is one of the important facilities to maintain safe navigations on NSR. Among the over 50 icebreakers in the world, the Russian icebreakers are the largest and most powerful. However, Russian icebreakers are also facing the problem of aging and over-served.

At present, there are four ports alongside NSR, Port Dickson, Port Dudinka, Port Tiksi, and Pevek Port. They are only available for ships with a daft under 10 meters. Also, these ports are lack of berthing facilities.

Navigational aid can mark dangerous waters, anchorage, restricted zone, etc. It is able to provide guided navigation routes for vessels and make it easier for seafarers to locate their ships. It is vital to safe navigation. However, there is merely no navigational aid to guide safe routes along Arctic routes.

GPS, logs, magnetic compasses, radars and some other common navigational aiding facilities could be used in the Arctic region. But, it may possibly fail to function properly due to geomagnetic storms. On the account of lacking necessary observatory facilities and hydrology data, there could always be limits to meteorology forecasts in the area, which make it hard to assist safe navigation through providing related information. Arctic maps cover a comparatively small area with a comparatively low accuracy. There is merely no map for waters above $75^{\circ}$ of north latitude. In addition, Sea Laptev and East Siberian Sea never experienced any systematic measurements due to severe icing. 


\section{ESTABLISHMENT OF NSR EVALUATION INDEX SYSTEM}

According to the analysis on different influence factors of NSR sailing condition, the article built up an evaluation index system. The article comes out with four main evaluation indexes, by working on principles of being scientific, target oriented, using systematical, practical, applicable and independent methods as well as using a combination of quantitative and qualitative measures. The four evaluation indexes are: natural environment, laws and regulations, geopolitics, navigation aiding facilities and information intelligence environment. Natural environment includes temperature, visibility, wind, velocity of currencies, intensity of sea ice, thickness of sea ice, depth of channels and distribution of straits. Laws and regulations include national laws and regulations or that of relevant costal countries as well as International norms of the international vessel sailing and vessel operating in the area. Geopolitics is mainly a combination of passage sovereignty, channel controlling power, coordinating ability of alongside countries and their political strategies. Navigation aiding facilities and information intelligence system mainly includes icebreakers, port facilities, navigational aid, navigational positioning equipment, sea charts as well as meteorological and oceanographic broadcasts. The evaluating index system is shown in Fig. 2 .

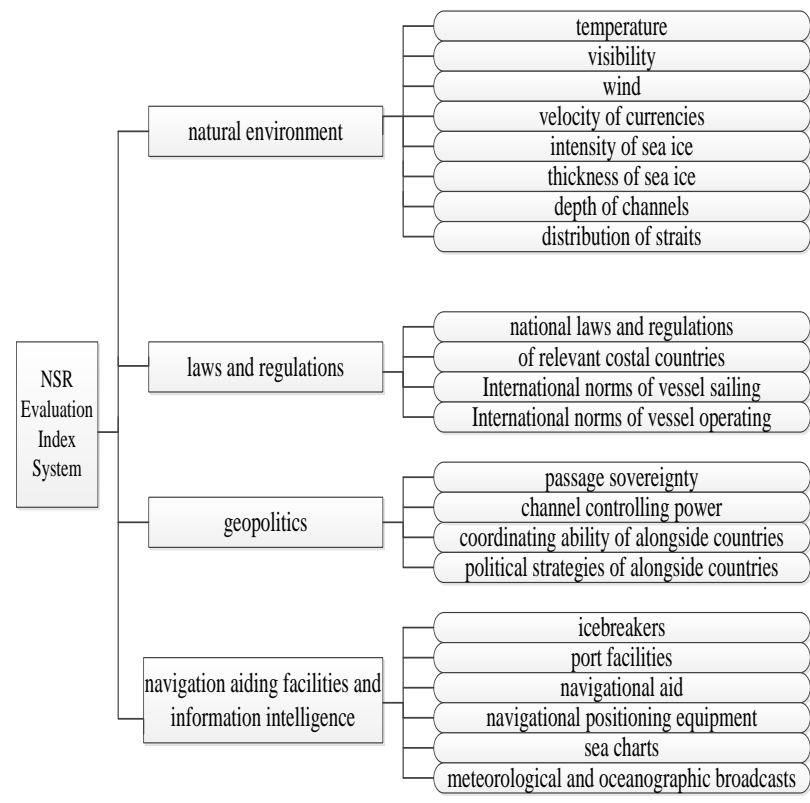

Figure 2. Index system for North Sea Route's navigation environment evaluation

Before evaluating the sailing condition, it is necessary to decide the weight of different indicators. There are two main methods to decide the weights which are the objective and subjective methods. Methods commonly used in objective weighting are Analytical Hierarchy Process, Delphi Evaluation, Binominal Coefficient Method, etc[17]. Meanwhile, Entropy Method, Principle Component Analysis and Multi-goal Planning are commonly used in subjective weighting. In view of the lack of accurate statistical data of indicators of the NSR evaluation index system, the method used to decide the weight is Analytical Hierarchy Process. To acquire the weight of each indicator, 10 experts in the field of Arctic research were invited. The calculation process is abridged, and the results are shown in Table I .

TABLE I. HE INDEX WEIGHTS OF NORTH SEA ROUTE'S NAVIGATION ENVIRONMENT EVALUATION

\begin{tabular}{|c|c|c|c|c|}
\hline & $\begin{array}{l}\text { First } \\
\text { class } \\
\text { indicators }\end{array}$ & $\begin{array}{l}\text { We } \\
\text { ight }\end{array}$ & $\begin{array}{l}\text { Second class } \\
\text { indicators }\end{array}$ & $\begin{array}{l}\text { Wei } \\
\text { ght }\end{array}$ \\
\hline & & & Temperature & $\begin{array}{l}0.05 \\
73\end{array}$ \\
\hline & & & Visibility & $\begin{array}{l}0.11 \\
01\end{array}$ \\
\hline & & & Wind & $\begin{array}{l}0.08 \\
81\end{array}$ \\
\hline & Natural & 0.4 & Velocity of current & $\begin{array}{l}0.12 \\
20\end{array}$ \\
\hline & Environment & 690 & Intensity of sea ice & $\begin{array}{l}0.22 \\
91\end{array}$ \\
\hline & & & Thickness of sea ice & $\begin{array}{l}0.27 \\
37\end{array}$ \\
\hline & & & Depth of channel & $\begin{array}{l}0.04 \\
56\end{array}$ \\
\hline & & & Distribution of straits & $\begin{array}{l}0.07 \\
42\end{array}$ \\
\hline & & & International laws and & 0.43 \\
\hline & & & regulations within & 0.30 \\
\hline Sea Route's & $\begin{array}{l}\text { Laws } \\
\text { and }\end{array}$ & 0.1 & relevant costal countries & 92 \\
\hline navigation & Regulations & 040 & $\begin{array}{l}\text { Ice zone vessel sailing } \\
\text { rules }\end{array}$ & $\begin{array}{l}0.10 \\
56\end{array}$ \\
\hline & & & Ice zone vessel & 0.15 \\
\hline & & & operating standards & 01 \\
\hline & & & Channel sovereignty & $\begin{array}{l}0.38 \\
73\end{array}$ \\
\hline & & & Channel control power & 0.27 \\
\hline & $\begin{array}{l}\text { Geopoliti } \\
\text { cs }\end{array}$ & $\begin{aligned} 0.1 & \\
484 & \end{aligned}$ & Political strategies of & $\begin{array}{r}48 \\
0.19\end{array}$ \\
\hline & & & relevant costal countries & 81 \\
\hline & & & Coordination ability of & 0.13 \\
\hline & & & relevant countries & 97 \\
\hline & & & Icebreakers & $\begin{array}{l}0.11 \\
16\end{array}$ \\
\hline & & & Port facilities & 0.27 \\
\hline & Navigati & & Navigational positioning & $\begin{array}{l}26 \\
0.17\end{array}$ \\
\hline & on aid and & 0.2 & facilities & 32 \\
\hline & Intelligence & 786 & Navaid & 0.13 \\
\hline & Environment & & 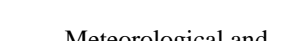 & 95 \\
\hline & & & oceanographic broadcasts & 76 \\
\hline & & & Charts & 0.21 \\
\hline & & & & 55 \\
\hline
\end{tabular}

\section{MODEL BUILDING OF NSR SAILING CONDITION EVALUATION}

\section{A. Selection of Evaluation Methods}

There are many methods to assess the sailing condition. Those recently used are Mathematical Statistics Methods, Gray Related Analysis, Analytic Hierarchy Process, Fuzzy Comprehensive Evaluation and Fault Tree Analysis, etc[1]. Each of these evaluations has its own characteristics and objectives. In this case, it is very important to comprehensively consider the applicability of the evaluating methods and the characteristics of different evaluating objects.

Gray clustering is an evaluation method which sums 
up clusters' whitening weight by different gray level, thereby judging clusters' gray level[18-19]. The focus of the study is the ambiguity of information, namely, the grayness. Regarding to the special location and severe natural environment of NSR, a lot of evaluation information is not clear and typically gray. At the meantime, it is necessary to turn qualitative indicators into quantitative value in certain ways when evaluating the sailing condition of NSR in which ambiguity and randomness will occur inevitably. Cloud models, as a kind of new conversion model, can greatly harmonize ambiguity and randomness. It can realize comprehensive conversion between qualitative and quantitative values and present the result in schematic diagram which has good visibility. Therefore, considering the grayness, ambiguity, randomness, complexity of the sailing condition in NSR, the article utilizes gray-cloud clustering as the evaluation tool.

\section{B. Evaluation Model Building}

Let $U(x)$ be a quantitative set of grades represented by an accurate value. $\mathrm{C}$ is a qualitative concept based on $U(x)$. Indicator $\mathrm{x}$ in $U(x)$ is a random value with a stable trend relative to the whitening weight of the gray concept that $\mathrm{C}$ presents. In addition, the distribution in the set of grades of whitening weight is called whitening weight gray-cloud or gray-cloud for short[20]. Peak value $C x$, left and right boundary value $(L x, R x)$ and entropy $E n$, excess entropy i.e. $G L(C x ; L x, R x ; E n ; H e)$ are used to indicate the digital feature of gray-cloud. Among these values, $C x$ best represents the qualitative concept, namely, its whitening weight in equivalence to 1 . It is the center value of NSR navigation condition safety level in the evaluation. The entropy $E n$ is the measurement of uncertainty of safety information of NSR sailing condition. The higher the entropy is, the higher the ambiguity and randomness of the information are, and vice versa. Excess entropy $\mathrm{He}$ is the measurement of uncertainty level of entropy in which

$$
\begin{gathered}
E n=\frac{(R x-L x)}{6} \\
H e=\frac{E n}{a}
\end{gathered}
$$

In the above function, $a$ is a given constant which equals to 6 . Because normal distribution is of unique mathematical characteristics and strong applicability, the article formulated the algorithm based on a normal distributional gray-cloud[21], and:

1) Generate expectation $C x$ and random normal distribution value $x_{i}$ which base on the standard deviation of $E \mathrm{n}$ in the interval [ $L x, R x$ ].

2) Generate expectation $E n$ and random value em which base on the standard deviation of $\mathrm{He}$.

3) Compute whitening weight $f_{i}=\exp \left[-\frac{\left(x_{i}-C x\right)^{2}}{2(e m)^{2}}\right]$

Based on the theory above, the evaluation ideas of the article are as following. Firstly, compute first grade indicator and categorize gray level based on expert scoring and weight computing. Secondly, set up whitening weight for normal distributional gray-clouds separately and compute their whitening weight. At last, obtain coefficients for clustering weights and come up with evaluation results. Specific algorithm is as follows:

- Determine Score $S_{i}$ as First Class Indicator

Due to the lack of objective and precise statistical values and comparison for selected NSR evaluating indicators, expert scoring is used in evaluating indicators. Scores are between $[0,1]$ in invited Arctic experts' scoring.

Suppose in NSR evaluating system there are $\mathrm{n}$ first class indicators $I_{i}(i=1,2,3, \cdots \cdots, n)$. There are $\mathrm{m}$ second class indicators $J_{j}(j=1,2,3, \cdots \cdots, m)$ affiliated to first class indicators $i$. Let the score for indicator $\mathrm{j}$ be $S_{i j}$, weight be $V_{i j}$. Set the product of $S_{i j}$ and $V_{i j}$ as score for $\mathrm{j}$. Sum up $\mathrm{m}$ indicators and generate the final score for first class indicator $S_{i}$. Then, score for first class indicator $\mathrm{i}$ is:

$$
S_{i}=\sum_{j=1}^{m} S_{i j} * V_{i j}
$$

\section{- Determine Center Value $\lambda_{i}^{w}$ of Gray Classes}

The NSR sailing condition evaluation aims at deciding whether it is possible to sail via NSR and its safety level. In this case, whether it is possible to sail through NSR and its safety level could set up the standard of evaluation set. The article set up five grey classes for NSR navigation, i.e. none navigable, unsafe sailing condition, general sailing condition, comparatively safe sailing condition and safe sailing condition. Let gray class set be $W$, correspond rapidly to grayness $[0,0.2],[0.2,0.4],[0.4,0.6],[0.6,0.8]$, $[0.8,1]$. Let center value be $\lambda_{i}^{w}$ equals to center value of each grey class. See Table II .

TABLE II. GREY CLASS CENTER VALUE OF THE EVALUATION INDEX

\begin{tabular}{|c|r|r|r|r|r|}
\hline \multirow{2}{*}{ Indicators } & \multicolumn{5}{|c|}{ Grey Classes } \\
\cline { 2 - 6 } & $\begin{array}{r}\text { None } \\
\text { Navigable }\end{array}$ & $\begin{array}{l}\text { Unsaf } \\
e\end{array}$ & $\begin{array}{c}\text { Gene } \\
\text { ral }\end{array}$ & $\begin{array}{c}\text { Comp } \\
\text { arably } \\
\text { Safe }\end{array}$ & Safe \\
\hline $\begin{array}{c}\text { Natural } \\
\text { Environment }\end{array}$ & 0.1 & 0.3 & 0.5 & 0.7 & 0.9 \\
\hline $\begin{array}{c}\text { Laws and } \\
\text { Regulations }\end{array}$ & 0.1 & 0.3 & 0.5 & 0.7 & 0.9 \\
\hline Geopolitics & 0.1 & 0.3 & 0.5 & 0.7 & 0.9 \\
\hline $\begin{array}{c}\text { Navigation } \\
\text { Aid and } \\
\text { Information } \\
\text { Intelligence }\end{array}$ & 0.1 & 0.3 & 0.5 & 0.7 & 0.9 \\
\hline
\end{tabular}

- Deciding Normal Distributed Whitening Weight Function $F_{i}{ }^{w}(\mathrm{x})$

Whitening weight function is a key factor in realizing expert scoring and quantitative analyzing in reality. Combining the above normal distributed greycloud modal functioning algorithm and center valued ${ }_{i}^{w}$, whitening weight function $W_{1}, W_{2} 、 W_{3}, W_{4} 、 W_{5}$ can be generated. See below. 


$$
\begin{gathered}
F_{i}^{1}(\mathrm{x})=\left\{\begin{array}{lc}
1 & 0 \leq x \leq 0.1 \\
\exp \left[-\frac{(x-0.1)^{2}}{2(e m)^{2}}\right] & 0.1 \leq x \leq 0.3 \\
0 & x \notin[00.3]
\end{array}\right. \\
F_{i}^{2}(\mathrm{x})=\left\{\begin{array}{lc}
0 & x \notin[0.10 .5], \\
\exp \left[-\frac{(x-0.3)^{2}}{2(\text { em })^{2}}\right] & 0.1 \leq x \leq 0.5
\end{array}\right. \\
F_{i}^{3}(\mathrm{x})=\left\{\begin{array}{lc}
0 & x \notin[0.30 .7] \\
\exp \left[-\frac{(x-0.5)^{2}}{2(\text { em })^{2}}\right] & 0.3 \leq x \leq 0.7
\end{array},\right. \\
F_{i}^{4}(\mathrm{x})=\left\{\begin{array}{lc}
0 & x \notin[0.50 .9] \\
\exp \left[-\frac{(x-0.7)^{2}}{2(\text { em })^{2}}\right] & 0.5 \leq x \leq 0.9
\end{array}\right. \\
F_{i}^{5}(\mathrm{x})= \begin{cases}0 & x<0.7 \\
\exp \left[-\frac{(x-0.9)^{2}}{2(\text { em })^{2}}\right] & 0.7 \leq x \leq 0.9 \\
1 & x \geq 0.9\end{cases}
\end{gathered}
$$

Schematic diagram for grey class whitening weight function $F_{i}^{w}(\mathrm{X})$ is shown in Fig.3.

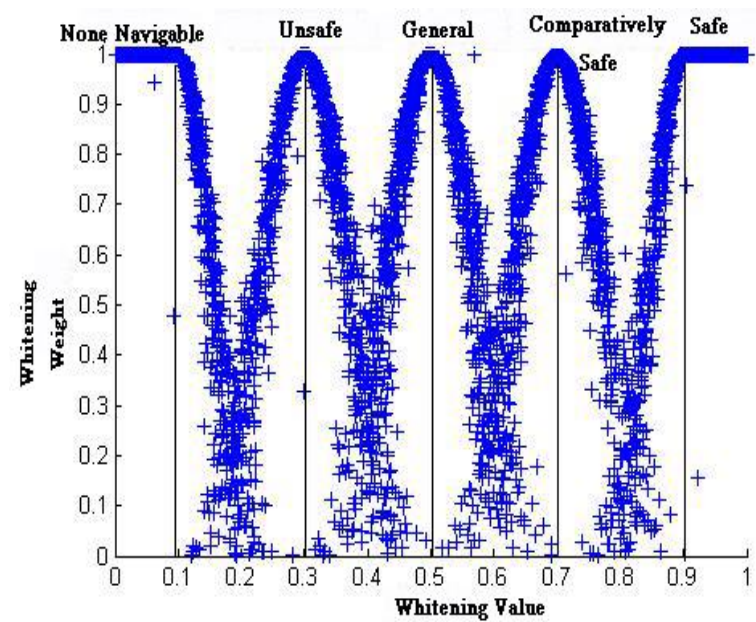

Figure 3. The schematic diagram of grey class whitening weight function

\section{- Calculation of Whitening Weight $f_{i}^{w}(x)$}

Suppose there are $\mathrm{Y}$ experts who are participating in scoring of NSR sailing condition indexes, $S_{i}(\mathrm{i}=1$, $2, \ldots, Y$ ) will generate correspondingly. Compute the geometric average ${ }^{\varphi_{i}}$ of $\gamma_{\text {scores and put them into }}$ whitening weight function $F_{i}^{w}(\mathrm{x})$. Run $F_{i}^{w}(\mathrm{x})$ function $h$ times and generate $h_{\text {whitening weight values. Then, }}$ let the final whitening weight $f_{i}^{w}(x)$ be the expectation of all whitening weight values.

$$
\boldsymbol{\varphi}_{i}=\frac{\sum_{1}^{\gamma} \sum_{j=1}^{m} \boldsymbol{S}_{i j} * \boldsymbol{V}_{i j}}{\mathrm{Y}}
$$

$$
f_{i}^{w}(x)=\frac{f_{i 1}^{w}(x)+f_{i 2}^{w}(x)+\cdots \cdot+f_{i h}^{w}(x)}{h}
$$

\section{- Deciding Weight to Index Clusters $\eta_{i}^{w}$}

Weights of index clusters are weights affiliated to different grey classes $W$ by using certain value to evaluate the tendency towards different grey levels of different indexes. Using center value $\lambda{ }_{i}^{w}$ of grey classes different indexes belong to, grey classes' clustering weight $\eta_{i}^{w}$ affiliated to different first grade indexes i can be determined. See functions below,

$$
\eta_{i}^{w}=\frac{\lambda_{i}{ }^{w}}{\sum_{i=1}^{n} \lambda_{i}{ }^{w}}
$$

- Calculation of Coefficient of Clusters

Coefficient of Clusters is used to describe the level of grayness that each evaluating object affiliates to. The higher the level is, the higher the possibility that the object is affiliated to the specific grey class would be. Let the NSR integrated cluster coefficient of grey class be $\sigma^{w}$. Five grey class coefficient sets $\sigma$ can be generated, note as $_{\sigma}=\left[\sigma^{1}, \sigma^{2}, \sigma^{3}, \sigma^{4}, \sigma^{5}\right]$. In which,

$$
\sigma^{w}=\sum_{i=1}^{n} f_{i}^{w}(x) * \eta_{i}^{w}
$$

- Calculation of Evaluation Result

Decide if NSR is navigable by judging which grey class a specific NSR sailing condition belongs to through analyzing clustering coefficients.

$$
\max _{1 \leq w \leq 5}\left\{\sigma_{k}^{w}\right\}=\sigma_{k}^{w}
$$

\section{Calculation and Result Analysis}

The following paragraphs calculates the final result of NSR sailing condition evaluation based on the weight of NSR sailing condition indexes and grey-cloud clustering evaluation method.

- Calculation of Scores of Indexes

To accurately estimate the indexes of actual condition of NSR sailing condition and to yield sufficient accuracy, the article invited fifteen experts including five IMO experts, five chief engineers of captains and five experts in shipping industry to score the influences of NSR sailing condition. Using function (2), final scores of first grade indexes are generated and shown in Table III.

TABLE III. FINAL SCORE OF THE FIRST CLASS INDEXES

\begin{tabular}{|r|r|r|r|c|}
\hline $\begin{array}{r}\text { Ex } \\
\text { pert }\end{array}$ & $\begin{array}{r}\text { Natural } \\
\text { Environment }\end{array}$ & $\begin{array}{c}\text { Laws } \\
\text { and } \\
\text { Regulations }\end{array}$ & $\begin{array}{c}\text { Geopolit } \\
\text { ics }\end{array}$ & $\begin{array}{c}\text { Navigation } \\
\text { Aid and } \\
\text { Information } \\
\text { Intelligence }\end{array}$ \\
\hline 1 & 0.2404 & 0.4205 & 0.3616 & 0.2756 \\
\hline 2 & 0.2341 & 0.4118 & 0.3853 & 0.3075 \\
\hline 3 & 0.2156 & 0.3118 & 0.4482 & 0.2794 \\
\hline 4 & 0.2403 & 0.3282 & 0.3843 & 0.2508 \\
\hline 5 & 0.2833 & 0.4888 & 0.3464 & 0.2844 \\
\hline 6 & 0.2585 & 0.2722 & 0.3035 & 0.3042 \\
\hline 7 & 0.2406 & 0.3956 & 0.3005 & 0.2950 \\
\hline 8 & 0.2776 & 0.2760 & 0.3442 & 0.2770 \\
\hline 9 & 0.2761 & 0.3094 & 0.3567 & 0.3391 \\
\hline
\end{tabular}




\begin{tabular}{|l|l|l|l|l|}
\hline 10 & 0.2924 & 0.3666 & 0.3346 & 0.3610 \\
\hline 11 & 0.2706 & 0.3520 & 0.3366 & 0.3111 \\
\hline 12 & 0.2795 & 0.3259 & 0.4599 & 0.2675 \\
\hline 13 & 0.2711 & 0.3254 & 0.3723 & 0.3600 \\
\hline 14 & 0.2865 & 0.3832 & 0.4666 & 0.2932 \\
\hline 15 & 0.2626 & 0.3154 & 0.3459 & 0.2851 \\
\hline
\end{tabular}

- Calculation of Whitening Weight

Calculate $\varphi_{i}$ by using function $4(Y=15)$, put the result the weight function and run 100 times. The whitening weight matrices corresponding to the NSR first class indexes are as follows:

$\left[\begin{array}{lllll}0.0136 & 0.8347 & 0.0039 & 0.0000 & 0.0000 \\ 0.0007 & 0.7260 & 0.0917 & 0.0000 & 0.0000 \\ 0.0003 & 0.5349 & 0.1676 & 0.0000 & 0.0000 \\ 0.0019 & 1.0000 & 0.0198 & 0.0000 & 0.0000\end{array}\right]$

- $\quad$ Setting Clustering Weights for Indexes

The clustering weight of when natural environment, laws and regulations, geopolitics as well as navigation and information intelligence affiliate to none navigable condition, unsafe sailing condition, general sailing condition, comparatively safe sailing condition, safe sailing condition are $0.04,0.12,0.20,0.28,0.36$.

- Calculating Comprehensive Clustering Coefficients

Clustering coefficients for each grey class can be generated as the following from function 7 ,

[ [ $\left.\begin{array}{lllll}0.0007 & 0.3715 & 0.0566 & 0.0000 & 0.0000\end{array}\right]$

- Results of Evaluation and Analysis

According to the clustering coefficient, $\max (\sigma)=0.3715$, which indicates that NSR sailing condition is none navigable.

\section{CONCLUSIONS}

This article systematically analyzes the natural environment, laws and regulations, geopolitics, assistant navigation equipment as well as information system of the NSR. An evaluation index system is established and, through which that the main factors affecting the safety of sailing on NSR are concluded as the relative to natural environment. The intensity and thickness of sea ice are the key factors among all the natural environment factors. By building up the grey-cloud clustering model, the article suggests that the NSR would still be unsafe for navigation. Merchant ships navigating via the NSR is facing severe challenges in the following aspects: firstly, the navigable period of NSR is short, and the ocean environment is severe with large scale of ice covering sea surface, glaciers, ice cube, floating ice and snow storms, which make the sailing condition unfavorable. Secondly, NSR is now lack of creditable data of navigating, e.g. data on meteorology, sea conditions, conditions of the channels, etc. Thirdly, the land-based support capability of NSR is weak, especially that the icebreakers and the construction of corresponding communication navigation facilities could not ensure the safe navigation of general merchant ships. Therefore, the safe navigation on NSR still requires the effort from all parties. More investments in infrastructure are needed to improve the navigating condition and further studies on NSR should also be carried out in the future.

\section{ACKNOWLEDGEMENT}

This work was supported by the National Natural Science Foundation of China (Grant No. 61473053) and the Fundamental Research Funds for the Central Universities.

\section{REFERENCES}

[1] J. F. He, R. R. Wu, F. Zhang, "The Progress of Expeditions and Research in the Seas related to the Arctic Passages[J]. Chinese Journal of Polar Research, vol. 2, pp. 91-100, 2012.

[2] L. Yan, "The Resarch on the Navigable Environment of Arctic Passage", Dalian: Dalian Maritime University,2010.

[3] Y. Q. Wang, J. M. Shou, "The Influnce of Northeast Passage Navigation to China's shipping industry", International Trade, vol. 29, pp. 186-188, 2012.

[4] C. J. Bai, Z. H. Li, Z. C. Yang, "Research of Arctic sea routes", Marine Technology, vol. 5, pp. 10-12, 2009.

[5] Z. F. Li, "Analysis of China's Strategy on Arctic Route”, China Soft Science, vol. 1, pp. 6-12, 2009.

[6] W. Q. Shang, "The Influence of the Northeast Passage Navigation Throughout the Year", China National Conditions and Strength, vol. 5, pp. 38-39, 2012.

[7] Xinhua.net, http://news.xinhuanet.com/overseas/2013-09/11/c_11 7325 225.htm, 2014-06-03

[8] Z. F. Li, L. Yan, M. Q. Xu, et al, "Evaluation of Arctic Route's Navigation Environment", Computer Engineering and Applications, vol. 1, pp. 253-257, 2013.

[9] J. Y. Chen, "Study on the Safety Assessment of Navigation Circumstance", Research on Waterborne Transportation, vol. 1, pp. 27-33, 2007.

[10] P. Q. Guo, "Research on International Issues in the Arctic Passages", Ocean Press, 2009.

[11] D. H. Zhang, "The Integrative Evaluation and Implement of Harbor Environment for the Opening of Navigation", Dalian: Dalian Maritime University, 2007.

[12] K. Liu, "SWOT Analysis of the Northeast Passage for China", Jinan: Shandong Normal University, 2013.

[13] Y. N. Li, "Chinese Cargo Ship Sets Sail For Arctic Short-cut", Zhejiang Daily, 2013-09-02 (20).

[14] Z. W. Li, J. T. Gao, "Analysis about the Legal Problems of Navigation in Arctic", Law Science Magazine, vol. 11, pp. 68-71, 2010.

[15] T. Y. Yan, "Current Legal System and the Trend of Improvement about the Arctic Routes", Academic Forum, vol. 2, pp. 139-144, 2011.

[16] Qianzhan.com,http://www.qianzhan.com/military/detail/275/1412 09-203d1793.html,2015-01-19.

[17] J. Liu, L. Sun, F. Wu, "Safety Evaluation Survey of the Maritime Traffic Environment", World Shipping, vol. 4, pp. 15-17, 2005.

[18] Y. H. Zhang, Y. J. Ma, C. T. Sun, "Application of Grey Clustering Method for Atmospheric Environmental Quality Assessment in Shenyang Economic Zone", Environmental Science \&Technology, vol. 33(S1), pp. 426-428, 2010.

[19] Y. S. Li, Z. J. Zhang, Y. H. Fei, "Application of an Improved Grey Clustering Method to Groundwater Quality Evaluation", Water Resources Protection, vol. 5, pp. 25-28, 2012.

[20] H. L. Wang, Y. Y. Feng, "Ablation Model Based on the Improved Gray Cloud and Its Applicant in the Gray Decision”, Journal of Natural Science of Heilongjiang University, vol. 6, pp. 740-745, 2006.

[21] H. M. Cai, J. Y. Chen, H. Y. Su, "Fault Diagnosis of Power Transformer Based on Grey Cloud Model", Power System Protection and Control, vol. 12, pp. 151-155, 2012. 